\title{
Biological Characteristics and Productivity of Sweet Sorghum Varieties in the Arid Conditions of Southeastern Kazakhstan
}

\author{
${ }^{1 *}$ Gulnaz Baiseitova, ${ }^{2}$ Gheorghe Moraru, ${ }^{3}$ Batyrbek Sarsenbayev, \\ ${ }^{4}$ Erlan Kirshibayev and ${ }^{1}$ Serik Kenenbayev \\ ${ }^{1}$ Kazakh National Agrarian University, Almaty, Republic of Kazakhstan \\ ${ }^{2}$ Institute of Genetics, Physiology and Plant Protection, Chisinau, Republic of Moldova \\ ${ }^{3}$ Institute of Plant Biology and Biotechnology, Almaty, Republic of Kazakhstan \\ ${ }^{4}$ Al-Farabi Kazakh National University, Almaty, Republic of Kazakhstan
}

Article history

Received: 13-11-2020

Revised: 01-04-2021

Accepted: 06-04-2021

Corresponding Author:

Gulnaz Baiseitova

Kazakh National Agrarian

University, Almaty, Republic

of Kazakhstan

E-mail: b.g.naz@mail.ru

\begin{abstract}
The research is aimed at studying the characteristics of growth, productivity and sugar content of Kazakh and foreign-bred sweet sorghum varieties and hybrids in the arid conditions of the southeast of Kazakhstan. The biometric and phenological characteristics of sweet sorghum varieties have been determined. Characteristics of soluble sugars accumulation and distribution in individual organs of sorghum have been shown. The promising varieties that are suitable for cultivation in the arid conditions of the southeast of Kazakhstan have been identified. Ultra-early ripening, high grain productivity, the heavy total biomass of the aboveground organs and high sugar content in the Medovoye variety make it possible to recommend its use in agro-industrial production and the breeding process. Among the early-maturing varieties of sweet sorghum, the Kazakhstanskoye-16 variety for its grain and biological productivity and sugar content in the conditions of rainfed agriculture can be recommended for practical use in crop production. In terms of the economically useful attributes, mid-season varieties, such as Rostovsky, Zubr, Dela-varieta, Simon, Kazakhstanskaya20, have been highlighted. These high-yield, high-sugar samples are recommended for cultivation without additional irrigation. As a conclusion, every group of sweet sorghum includes promising varieties and hybrids for practical use in the arid conditions of the southeast of the Republic.
\end{abstract}

Keywords: Biological Productivity, Drought Resistance, Soluble Sugars, Sorghum saccharatum (L.) Pers., Sweet Sorghum

\section{Introduction}

The global climate change accompanied by temperature growth, reduced water resources, reduced precipitation and increased area of drought zones and desertification is one of the key environmental problems of the Earth. It is a serious reason for searching and identifying the most drought-resistant, heat-resistant and at the same time high-yielding crops for satisfying the needs of food and fodder production and production of alternative renewable energy in the new environmental conditions (Sarsenbayev et al., 2013). One of the promising crops in these conditions is sorghum of all kinds-grain, sugar, technical and herbaceous Recently, however, the growing shortage of food, particularly in developing countries, the development of animal breeding, the need to provide food for this industry, as well as the widespread development of green energy technology (biofuel production) have made scientists and specialists pay a special attention to sweet sorghum. This is because this crop is multipurpose; it features high biological productivity and plasticity in changing environmental factors.

Cultivation of sweet sorghum in Kazakhstan can greatly help save irrigation water (resource-saving), restore soil fertility (desalinization, improvement of the water-physical properties), improve the environment (regulation of the atmosphere humidity and temperature, the $\mathrm{O}_{2} / \mathrm{CO}_{2}$ balance), provide liquid sugar to the population and fodder for animal breeding and solve the energy problem in the region (biofuels) (Baiseitova et al., 2019).

Sweet sorghum (Sorghum bicolor (L.) Moench) is a tall grassy plant with the C-4 type of photosynthesis, which reproduces by seeds and has a massive stem with 
sweet juice. Depending on the available infrastructure and the needs of the market, the juice can be processed into food syrup and all biomass can be converted into renewable fuels, while the seed cake can be used for making fuel pellets or feed for livestock breeding (Khalil et al., 2015; Mathur et al., 2017; Perrier et al., 2017; Shukla et al., 2017).

Due to its drought, heat and salt resistance, sweet sorghum is a promising alternative feedstock for biofuel production; sorghum reacts to stress more efficiently than traditional crops and is very promising for biomass production (Ekefre et al., 2017; Yucel and Erkan, 2020).

Sweet sorghum grows to a height of 120 to $400 \mathrm{~cm}$, depending on the variety and the cultivation conditions. It consists of leaf substance (about 19\%), juice (37\%), seeds $(8 \%)$ and wet base pulp $(36 \%)$. The yield rate of sweet sorghum ranges from 32 to $112 \mathrm{t} /$ ha (fresh biomass), or from 15 to 25 t/ha (dry biomass), depending on the variety, the climate, the location and the production practices (Bellmer et al., 2010).

Sweet sorghum grows fast (the life cycle is about 95 to 150 days) and features high biomass yield. Besides, it efficiently uses the soil moisture and usually requires only one-third of the amount of water compared to sugar cane and half of the amount compared to corn. Since sweet sorghum can adapt to various environments and has low needs for mineral fertilizers, it is widely grown around the world (Hu et al., 2017).

The juice of sweet sorghum contains soluble sugars (12 to 20\%), which include sucrose, glucose and fructose (Khalil et al., 2015; Ekefre et al., 2017). For the content of sugars, the juice from the stems of sweet sorghum is not inferior to the juice of sugar cane, while its composition is significantly different. By its composition, the sugar obtained from sorghum is superior to the sugar obtained from sugar beet and cane, since it also contains fructose and even glucose on top of sucrose. This juice can be used for obtaining $75 \%$ concentration syrup with a high content of fructose and glucose, which are highly valuable (Boldyreva and Britvin, 2015).

For the content of biologically active substances, the syrup obtained from sugar sorghum is close to natural honey and can be used in confectionery and bakery industries, as well as for the production of alcohol. The syrup obtained from sorghum stems contains $\mathrm{Ca}, \mathrm{P}$, $\mathrm{Mg}, \mathrm{K}, \mathrm{Na}, \mathrm{Cu}, \mathrm{Zn}, \mathrm{Co}, \mathrm{Mn}, \mathrm{Fe}, \mathrm{S}$, protein (up to $3 \%$ ), all essential amino acids, vitamins B1, B2, PP, E and C (Oros et al., 2010).

In the world agriculture, sorghum ranks fifth among the most widely used cereal crops; it is cultivated in more than 85 countries in the area of about 50 million ha. The main producers of sorghum grain are India (6.2 to 18.2 million ha), Nigeria (2.1 to 6.9 million ha), Sudan (1.5 to 7.1 million ha) and the USA (1.9 to 6.5 million ha). In other countries, sorghum is cultivated in the area of
14 to 18 million ha (32.6 to $41.9 \%$ ) (Rutto et al., 2013; Kovtunova and Kovtunov, 2016). The spread of sorghum in the world is evidence of its great potential. Due to the origin and the diversity, even in the aridest and hottest regions of the world, unlike other crops, sorghum allows obtaining consistently high yields of grain and green mass. This makes it a leading fodder and food crop (Alabushev et al., 2017). In Kazakhstan, this crop is cultivated in small areas and is considered only as a source of fodder.

Being a C-4 plant, sweet sorghum has a high photosynthetic capacity and can form large amounts of energy-rich biomass in a short time (Tang et al., 2018).

Therefore, expanding the areas used for sorghum is one of the reserves for increasing crop production and strengthening the forage base of livestock breeding.

Breeding and introduction of the most productive varieties and hybrids of sweet sorghum will help improve not only the forage base of livestock breeding, the needs of the food industry and energy production, but will also ensure the rational use of the lands with poor irrigation and drainage condition.

This being said, the aim was studying the productivity of domestic and foreign-bred sweet sorghum varieties and hybrids in the competitive conditions of the rainfed agriculture of the southeast of Kazakhstan.

\section{Materials and Methods}

The field experiments with sorghum were laid in 2016-2018 in the foothill zone, on light-brown soils (the thickness of the fertile horizon was $50 \mathrm{~cm}$ with the humus content of 2.7 to $3 \%$ ), without irrigation, on the territory of the Main Botanical Garden of the Institute of Botany and Phytointroduction of the Ministry of Education and Science of the Republic of Kazakhstan (Almaty, Southeast of Kazakhstan). During this time, the experiments were carried out in 3-fold repetition annually.

The soils are leached from carbonates to a considerable depth of 90-95 $\mathrm{cm}$. They are characterized by a slightly acidic, close to neutral reaction of the environment. In terms of particle-size distribution (Permitina, 2016), the soils of experimental areas are represented by medium loams.

In terms of moisture content, it belongs to the arid zone with the development of steppe landscapes. The Botanical Garden, in terms of natural zoning, belongs to the steppe zone of the foothills of the Zailiyskiy Alatau. The humus content in the upper horizons is 3.5-4.5\%. The soils are not alkaline, not salinized with readily soluble salts. The thickness of the fertile horizon is $50 \mathrm{~cm}$ (Permitina, 2016).

In this study, varieties and hybrids of sugar sorghum (Sorghum saccharatum (L.) Pers.) from the collection of the Laboratory of Plant Physiology and Biochemistry, Institute of Plant Biology and Biotechnology of Science 
Committee of the Ministry of Education and Science of the Republic of Kazakhstan were used.

When laying the experiments, the main attention was paid to the method of field experiment (Dospekhov, 2012). Sowing was done by hand on an area of $300 \mathrm{~m}^{2}$, in a wide-row method. After the soil preparation, in the first decade of May when the soil temperature reached 13$150^{\circ} \mathrm{C}$, the seeds ( 3 pcs per well) were sown to the depth of 4 to $5 \mathrm{~cm}$. The distance between the rows was $70 \mathrm{~cm}$ and between the plants $-30 \mathrm{~cm}$. Each variety had three rows in microplot containing 30 sorghum plants. Ten days after sowing, weeding from agrestal weeds was carried out, the phenological observation of the crops was performed and the timing of the onset of growth and development phases was recorded. Plants were grown without additional watering during the growing season until the grain was fully ripe.

During the vegetation period, phenological monitoring was performed. The vegetation period was assessed by noting the timing of the emergence, the beginning of tillering, the flag leaf emergence, ear emergence, the beginning and the end of flowering and state of grain ripeness (milky, wax and full). The growth parameters, such as the plant height, the panicle length, the number of knots, the number of lateral shoots and the biomass distribution in individual organs were determined by measuring and gravimetry after drying at $60^{\circ} \mathrm{C}$ to constant weight.

To determine the final growth parameters, three plants were randomly selected from three rows of each genotype of sugar sorghum at the end of the growing season. The height of the stem and its diameter at the level of the lower internode, as well as the length of the leaf and panicle were expressed in $\mathrm{cm}$. Leaves and panicles were separated from the stems and each organ was weighed separately after drying to constant weight at a temperature of $60^{\circ} \mathrm{C}$ for use in determining the patterns of biomass distribution among organs of plants. The number of leaves and nodes was calculated separately for the main and lateral shoots.

The content of water-soluble sugars in field conditions was determined using a portable ATAGO N1 (Japan) refractometer.

Separate internodes of the main and lateral shoots were analyzed. To determine the water-soluble sugars, internodes from three plants were used in the milky-wax ripeness of the grain according to a random sample. During this period, the plants accumulate the greatest amount of sugars. (The research methodology consists in cultivating varieties of sugar sorghum in competitive conditions and identifying the features of phenology, biological productivity and sugar content in order to develop practical recommendations for production).

The obtained results were statistically analyzed in the $\mathrm{R}$ programming language ( $\mathrm{R}$ version 3.2 .3 (2015-12-10) -
"WoodenChristmas-Tree") with open source and environment. Standard parametric tests, analyses were performed and statistical significance was determined using built-in and additional packages (dplyr, ggplot2, psych, etc.).

\section{Results and Discussion}

\section{The Biological Productivity of Sweet Sorghum Varieties in the Arid Conditions of Southeastern Kazakhstan}

Systematic studies of sugar varieties of identifying promising for cultivation in arid conditions of the southeast of Kazakhstan and use in the selection process have not been conducted. There are occasional developments on the creation of drought-resistant forms of sugar sorghum for the southeast of Kazakhstan (Omarova et al., 2016; Kovtunova and Kovtunov, 2016) and environmental testing of domestic and foreign genotypes in various regions of the country (Zhapayev et al., 2014). The phenological observations and measurements of the biometric parameters are shown in Table 1. Based on the obtained data, the studied varieties were divided into four groups: Ultra-fast ripening (93 to 100 days), fast ripening (107 to 114 days), mid-season (120 to 125 days) and lateripening (130 or more days). According to statistical data, the members of these groups differed significantly among themselves in terms of productivity and sugar content in the stems (Table 1). Mid- and late-ripening varieties were distinguished by more massive stems mainly due to their thickness and the number of internodes. Representatives of mid-ripening varieties were also distinguished by a high sugar content of the stems by the end of the growing season.

\section{Characteristic of the Ultra-Fast Ripening forms of Sweet Sorghum in the Conditions of Rain-Fed Cultivation}

The ultra-fast ripening varieties are Stavropol-36, Debut, Sever, Ayushka, Sazhen, Alga and Medovoe bred in Russia, as well as Karabosh from Uzbekistan and some hybrids. Plant height ranged from 135 (hybrid Nizkorosloye-81× Kazakhstanskoye-16) to $256 \mathrm{~cm}$ (Alga). The number of internodes (and leaves) ranged from 8 to 11 on the main stem. The number of lateral shoots was 0 to 4 . Measuring the parameters of the fourth leaf in the panicle, the most developed and photosynthetically active in the period of grain filling, showed that the length of the leaf ranged from 61 to $90 \mathrm{~cm}$ (hybrid Nizkorosloye-81× Stavropol36). The maximum leaf width was observed in the Medovoye variety-10.1 cm. The Sever variety had the narrowest $(6.7 \mathrm{~cm})$ leaf blade. By the stem thickness of the main shoot at the base, the Sazhen variety stood out $(2.0 \mathrm{~cm})$. Hybrids based on crossing the CMS line with sugar varieties had the thinnest stems $(1.5 \mathrm{~cm})$. 


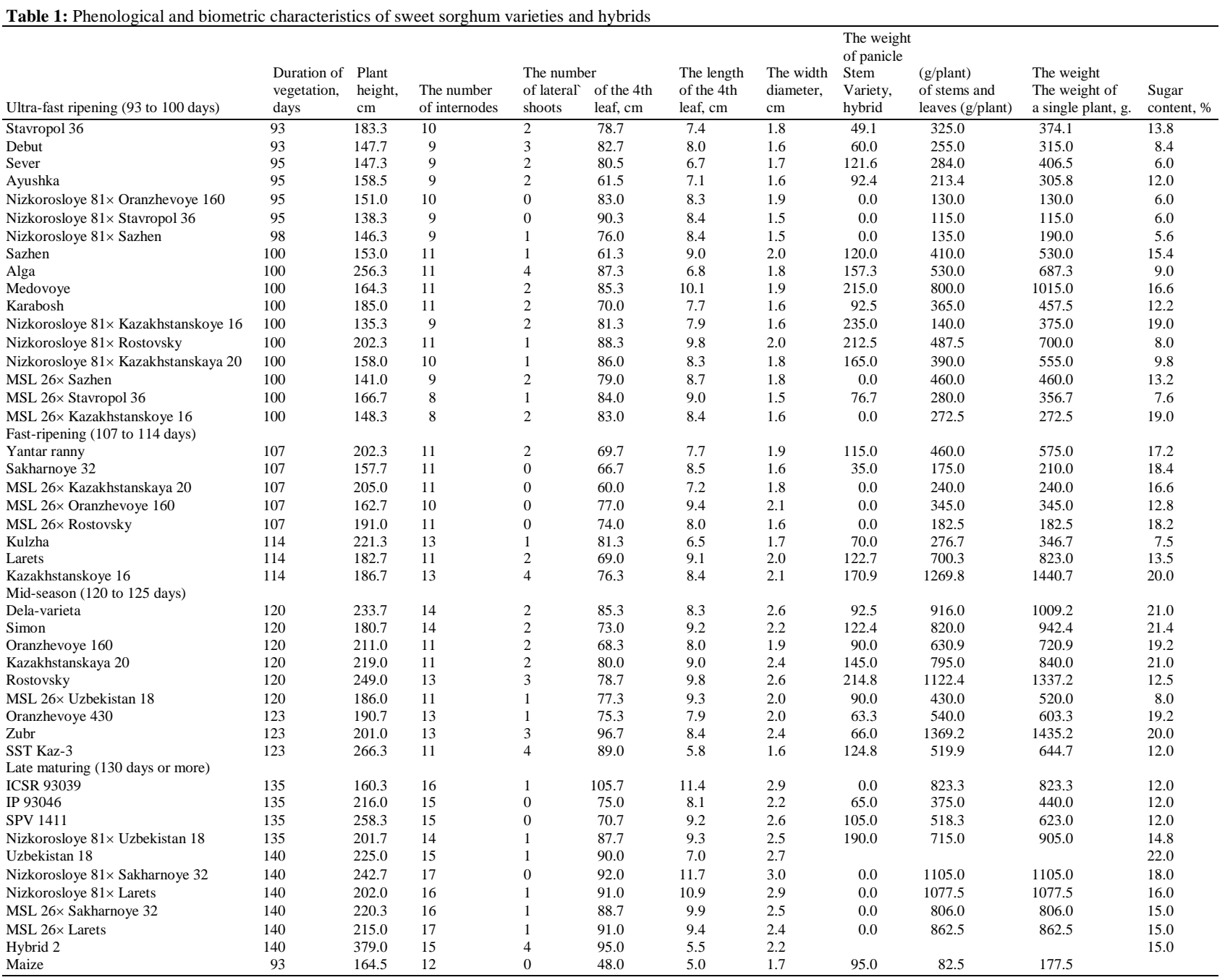

Among the ultra-fast ripening forms, the highest sugar content in the stems was noted in the hybrid obtained from crossing the CMS line with variety Kazakhstanskoye-16, which showed $19 \%$ of soluble sugars. In the conditions of rain-fed cultivation, the ultra-fast ripening variety Medovoye had the highest (16.6\%) sugar content in the stems. The studied ultra-fast ripening varieties also differed in grain productivity and the weight of the biomass of aboveground organs. High grain yield was characteristic of the Medovoye variety and the hybrids obtained by crossing the sterile Nizkorosloye- 81 line with Kazakhstanskoye 16 and Rostovsky. High grain productivity, the total weight of the biomass of the aboveground organs and sugar content of variety Medovoye make it attractive for use in the breeding process.

Thus, among the ultra-fast ripening forms of sweet sorghum, the hybrids based on CMS and the Medovoye variety stand out and can be recommended not only for practical use in breeding, but also for cultivation in the arid conditions.

\section{Fast Ripening Varieties and Hybrids}

This group includes Yantar Ranny, Sakharnoye-32, Kulzha, Larets, Kazakhstanskoye-16 and the hybrids obtained with the use of sterile line MSL-26 crossed with Kazakhstanskaya-20, Oranzhevoye-160 and Rostovsky varieties. The plant height in this group was 158 (Sakharnoye-32) to $221 \mathrm{~cm}$ (Kulzha). The number of leaves ranged from 10 to 13 on the main shoot. The highest tillering was noted in the Kazakhstanskoye-16 variety. The longest leaf $(81.0 \mathrm{~cm})$ also belonged to the Kulzha variety. However, it also was the narrowest $(6.5 \mathrm{~cm})$, whereas, in the Larets variety, the leaf width was $9.1 \mathrm{~cm}$. Stem thickness in this group ranged from 1.6 (variety Sakharnoye-32) to $2.1 \mathrm{~cm}$ (Kazakhstanskoye-16). High grain productivity also belonged to variety Kazakhstanskoye-16 $(171 \mathrm{~g})$. For this indicator, the group significantly lagged behind the ultra-fast ripening varieties. By the biomass of the above-ground organs, Kazakhstanskoye-16 variety was far ahead $(1,441 \mathrm{~g} / \mathrm{plant})$ of all other varieties and hybrids. Thus, among the early-ripening sweet sorghum varieties, 
Kazakhstanskoye-16 in the conditions of rainfed agriculture in terms of grain and biological productivity and sugar content $(20 \%)$ was highlighted from the rest of the varieties and could be recommended for practical use in crop production and plant breeding.

\section{Mid-Season Varieties and Hybrids}

This group included varieties and hybrids with the duration of the vegetation period of 120 to 125 days. These are "foreigners" like Dela-varieta, Simon and varieties of the CIS and domestic breeding-Oranzhevoye160, Oranzhevoye-430, Rostovsky, Zubr, Kazakhstanskaya-20, SST Kaz-3, hybrid MSL-26× Uzbekistan-18. The maximum plant height of SST Kaz-3 (i.e., Sorghum-Sudan grass) reached $266 \mathrm{~cm}$ without watering. The number of internodes and, respectively, leaves, was from 11 (Oranzhevoye 160, Rostovsky, Kazakhstanskaya-20, SST Kaz-3) to 14 (Dela-varieta, Simon), medium bushy-from one to four (SST Kaz-3) shoots. By the length of the leaves, Zubr variety was highlighted $(96.7 \mathrm{~cm})$ and by the width-Rostovsky variety $(9.8 \mathrm{~cm})$. For grain productivity, Rostovsky variety was ahead of all other varieties. The greatest amount of biomass in the above-ground organs was contained in varieties Zubr $(1,435 \mathrm{~g})$ and Rostovsky (1,337 g). Sugar content in the stems ranged widely-from $8 \%$ (the MSL-26× Uzbekistan-18 hybrid) to $21.4 \%$ (Simon variety). In general, among the mid-season varieties, the attention of specialists is attracted to the economically useful characteristics of the following sorghum varieties: Rostovsky, Zubr, Dela-varieta, Simon and Kazakhstanskaya-20. These high-yield and high-sugar samples were recommended for cultivation in the conditions of the southeast of Kazakhstan without additional irrigation.

\section{Late-Maturing Varieties and Hybrids}

As a rule, late-maturing varieties are characterized by extremely high biological productivity and, consequently, a high yielding of soluble sugars per unit area. This group includes the varieties and lines imported from warm countries like India (ICSR 93039, IP 93046, SPV 1411), Uzbekistan (Uzbekiston-18) and some hybrids obtained in the laboratory. Many of these varieties failed to ripen in the conditions of the Almaty region. A characteristic feature of this group is the abundance of leaves (internodes); weak lateral shoots formation activity and the absence of grains in the panicles. In the rainfed cultivation of sorghum, the hybrid line from India ICSR 93039 formed a leaf blade with the length of $105.7 \mathrm{~cm}$ and the width of $11.4 \mathrm{~cm}$. The hybrid obtained by crossing Nizkorosloye 81 sterile line with Sakharnoye 32 sweet variety had even wider $(11.7 \mathrm{~cm})$ leaves. However, they had smaller leaf blade length $(92.0 \mathrm{~cm})$.
Due to the abnormal climatic conditions in the 2018 summer (arid and hot with the early cold onset), in the plants in this group, the development of generative organs significantly lagged behind that of the other groups. Only the lines from India IP 93046, SPV 1411 and the Nizkorosloye-81× Uzbekistan-18 hybrid formed panicles and featured grain productivity. All members of the group were highlighted for the biomass productivity of the aboveground organs, which was evidence of their high potential. Plants of this group, in addition to the Uzbekistan-18 (22\%) variety and the Nizkorosloye-81× Sakharnoye-32 $(18 \%)$ and Nizkorosloye- $81 \times$ Larets $(16 \%)$ hybrids, are also characterized by low content of soluble sugars in the stems. It is known that the maximum content of soluble sugars in the stems is observed in the phase of grain milky-wax ripeness. By the time of harvesting, many varieties of this group failed to reach the state of milky-wax ripeness. This is the reason for low sugar content in the late-ripening varieties of sorghum.

In this group, promising varieties can be identified for practical use in terms of productivity and sugar content. These are Uzbekistan-18, hybrids Nizkorosloye-81× Uzbekiston-18, Nizkorosloye 81× Sakharnoye-32 and Nizkorosloye- $81 \times$ Larets.

Thus, a conclusion can be made that every group of sweet sorghum includes promising varieties and hybrids for practical use in the arid conditions of the southeast of the Republic. The research work for studying the samples and identifying the most promising forms should be continued in various ecological and climatic conditions of the south and the southeast of Kazakhstan.

\section{The Regularities of Soluble Sugars Accumulation and Distribution in the Stems of Sweet Sorghum Varieties}

In the modern conditions of climatic changes and scarcity of freshwater resources for obtaining sugar products and biofuels, it is advisable to cultivate sweet sorghum-the most drought-resistant of all known crops. It is a natural sugar bearer that accumulates up to 20 to $22 \%$ and more soluble sugars in the stems, making it a potential source of raw materials for the food industry and technical purposes (Rooney et al., 2007; Ionova, 2011). Throughout the world, there are about 4,000 varieties of sweet sorghum (Rutto et al., 2013); they differ in productivity, resistance to the adverse environmental factors and the content of soluble sugars in the stems. Therefore, studying the regularities of soluble sugars accumulation and distribution in the organs and regulation of their content is of both theoretical and practical interest.

First of all, it was necessary to determine the characteristics of soluble sugars accumulation in the main and the lateral shoots. Our findings suggested that the studied 
sweet sorghum varieties differed by the distribution of sugars between the main and lateral shoots (Table 2). All studied varieties can be divided into three groups: (a) Accumulating sugars predominantly in the main stem, (b) accumulating sugars in the lateral shoots and (c) evenly distributing sugars accumulation between the main and lateral shoots. Of the 24 genotypes, four varieties accumulated soluble sugars in the main stem (Larets, Zubr, Oranzhevoye 430 and Uzbekiston18). The vast majority of varieties (15) accumulated sugar in the lateral shoots (Stavropol-36, Sever, Ayushka, Alga, Debut, Medovoye, Sazhen, Kazakhstanskoye -16,
Oranzhevoye-160, Rostovsky, Kazakhstanskaya-20, Simon, Dela-varieta, Sugardrip and hybrid ICSR-93039). Two genotypes (Karabash, Yantar Ranny) featured uniform distribution of sugars between the main and the lateral shoots. Three genotypes (Sakharnoye-32, IP-93046, SPV1411) were incapable of tillering in the conditions of rainfed cultivation, though the feed area for all of them was the same. Given the fact that the tillering of cereals is a genetically determined trait, the identified features of the varieties are of great importance in creating new sorghum varieties with high sugar content.

Table 2: The content of soluble sugars in the internodes of the main and the lateral shoots of sorghum, (\%)

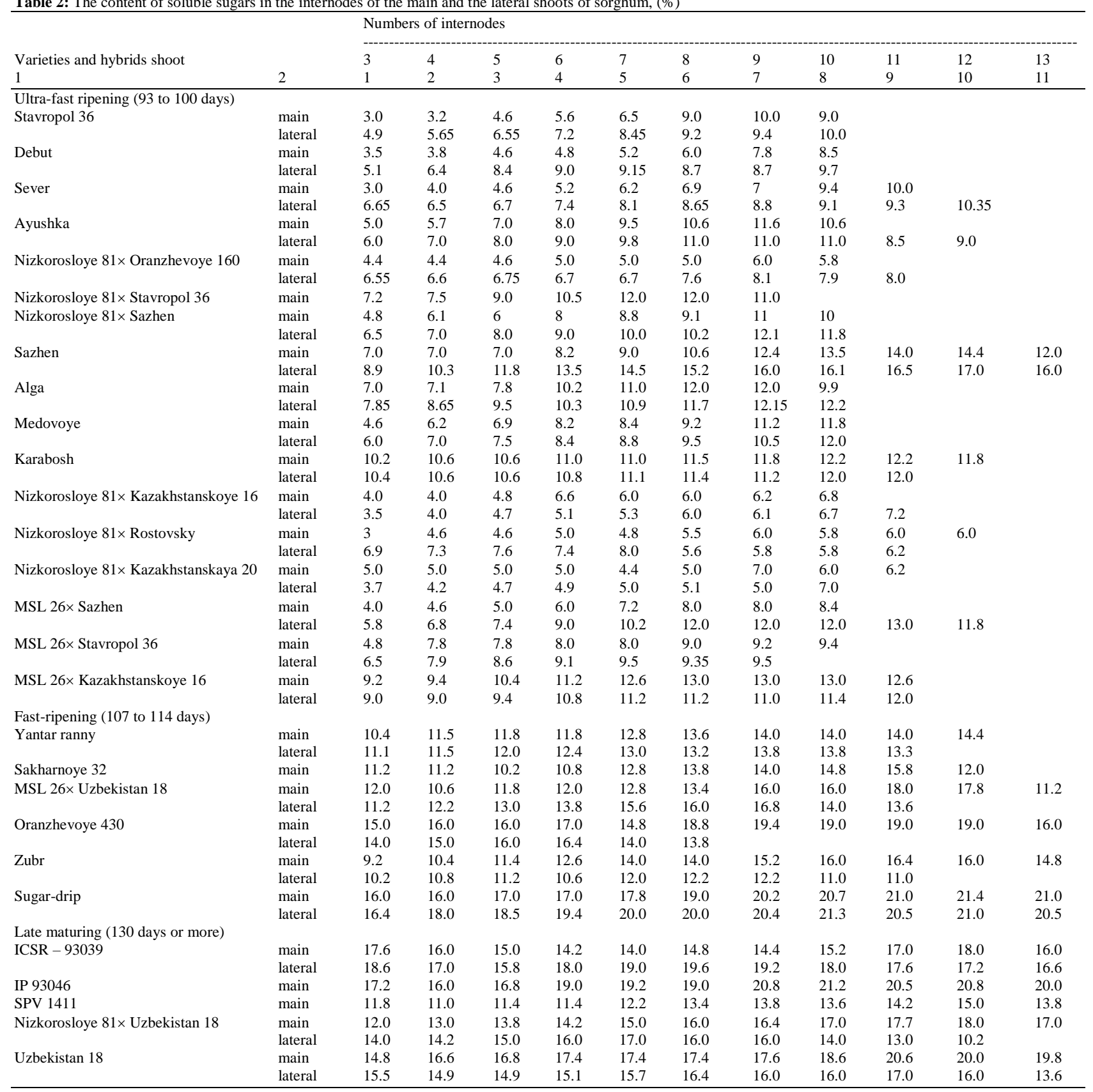


Next, the content of sugar in individual internodes of the main and the lateral shoots of sweet sorghum varieties was studied. As one can see from Table 2, sugar content in individual internodes on the main and the lateral shoots complies with the general regularity: The number of internodes increased up to seven to ten below at the base and decreased closer to the panicle. Such a pattern of sugars accumulation in the internodes is quite understandable. Each internode has its photosynthetic apparatus (leaf blade), the functional activity of which determines the level of sugar in it. By the end of the vegetation season, the lower leaves at the end of their growing season pass from the state of donors of photoassimilates to the state of consumers of the photoproducts from the upper leaves for maintaining life activity.

This explains low sugar content in the lower internodes. Low sugar content in the upper internodes is associated with the outflow of photoproducts for the formation of panicles and grain filling. Therefore, the maximum content of sugar is observed in sorghum internodes seven to ten. The highest content of sugars in the fast-ripening varieties was noted in nodes seven to eight, while in the mid-season varieties, it was noted in internodes nine to ten. The mid- and late-season varieties and hybrids had high sugar content. These are Simon (22.8\%), Kazakhstanskaya-20 (22.4\%), Sugar drip (21.4\%), IP 93046 (21.3\%) and Uzbekistan-18 (20.6\%). These varieties and hybrids are also highly productive.

\section{Conclusion}

A conclusion can be made that for practical use in the arid conditions of the southeast of Kazakhstan, the locally bred varieties with high sugar content Kazakhstanskaya20, Kazakhstanskoye-16, the high yielding and sugarcontaining Uzbekistan-18, ICSV-25274, SPV1411, Simon and Sakharnoye-32 are very important, same as the highly productive varieties with low content of sugars in the stems, such as Rostovsky and Zubr. The obtained results can be recommended for practical use in food industry, fodder and bioenergetics.

\section{Acknowledgement}

The authors received no financial support for the research.

\section{Author's Contributions}

All authors equally contributed in this study.

\section{Ethics}

This article is original and contains unpublished material. The corresponding author confirms that all other authors have read and approved the manuscript and no ethical issues have been involved.

\section{References}

Alabushev, A.V., Shishova, E. A., Romanyukin, A. E., Ermolina, G. M., \& Gorpinichenko, S. I. (2017). The origin of sorghum and the development of its breeding. Scientific Journal of KubSAU, 127(03), 281-294. https://doi.org/10.21515/1990-4665-127-017

Baiseitova, G. A., Sarsenbayev, B. A., \& Kirshibayev, E. A. (2019). Productivity of sweet sorghum varieties in the conditions of the southeast of Kazakhstan. In: Theoretical and practical aspects of research studies (Volume 3) Materials of International (correspondence scientific-practical) conference, Vostretsov, A.I. (Ed.), Izdatelsko Kashta "SORoS", Sophia; RIO SRC Mir Nauki, Neftekamsk, pp: 173-177. http://sciencepeace.ru/files/TPANI_2019.pdf

Bellmer, D., Huhnke, R., Whiteley, R., \& Godsey, C. (2010). The untapped potential of sweet sorghum as a bioenergy feedstock. Biofuels, 1(4), 563-573. https://doi.org/10.4155/bfs.10.34

Boldyreva, L. L., \& Britvin, V. V. (2015). Creation of new forms the sweet sorghum for a production of sugar syrup. News of Agricultural Science Tavrida, 1(164), 56-62. https://www.elibrary.ru/item.asp?id=26374150

Dospekhov, B. A. (2012). Methodology of field experiments (with the bases of the research results statistical processing). Agropromizdat, Moscow.

Ekefre, D. E., Mahapatra, A. K., Latimore Jr, M., Bellmer, D. D., Jena, U., Whitehead, G. J., \& Williams, A. L. (2017). Evaluation of three cultivars of sweet sorghum as feedstocks for ethanol production in the Southeast United States. Heliyon, 3(12), e00490. https://doi.org/10.1016/j.heliyon.2017.e00490

Hu, S. W., Wu, L. M., Persson, S., Peng, L. C., \& Feng, S. Q. (2017). Sweet sorghum and Miscanthus: Two potential dedicated bioenergy crops in China. Journal of Integrative Agriculture, 16(6), 1236-1243. https://doi.org/10.1016/s2095-3119(15)61181-9

Ionova, L. P. (2011). Effect of Density Standing on the Accumulation of Sugars in the Juice of Sweet Sorghum Stem in the Arid Zone. Agricultural Sciences, Advances in Current Natural Sciences, 5, 82-84. https://naturalsciences.ru/en/article/view?id=21466

Khalil, S. R., Abdelhafez, A. A., \& Amer, E. A. M. (2015). Evaluation of bioethanol production from juice and bagasse of some sweet sorghum varieties. Annals of Agricultural Sciences, 60(2), 317-324. https://doi.org/10.1016/j.aoas.2015.10.005

Kovtunova, N. A., \& Kovtunov, V. V. (2016). The use of sorghum and the main areas of breeding work in ARRIGC named after IG Kalinenko. Taurida Herald of the Agrarian Sciences, (3), 7.

Mathur, S., Umakanth, A. V., Tonapi, V. A., Sharma, R., \& Sharma, M. K. (2017). Sweet sorghum as biofuel feedstock: recent advances and available resources. Biotechnology for Biofuels, 10(1), 1-19. https://doi.org/10.1186/s13068-017-0834-9 
Omarova, A. S., Omarova, A. A., \& Akhmetova, N. E. (2016). Study of biochemical traits of sorghum crops samples. In: Proceedings of the International Scientific Conference "The system of creating livestock forage base through intensification of plant production and the use of natural pastures", pp: 144-146.

Oros, G. Y., Selemenev, V. F., Krisilova, E. V., Korneeva, R. N., Buneeva, N. M., Lukin, A. N., Zarodin, G. S., \& Kiselev, I. Y. (2010). Colored substances of sugarcontaining solutions sorgo. Sorbtsionnye i Khromatograficheskie Protsessy, 10(4); 598-601. https://journals.vsu.ru/sorpchrom/article/view/2084

Permitina, V. N. (2016). Formation of soil cover in the conditions of the introduction of tree species of the Botanical Garden. Soil Science and Agrochemistry, 2, 17-27. https://elibrary.ru/item.asp?id=42394113

Perrier, L., Rouan, L., Jaffuel, S., Clément-Vidal, A., Roques, S., Soutiras, A., ... \& Luquet, D. (2017). Plasticity of sorghum stem biomass accumulation in response to water deficit: a multiscale analysis from internode tissue to plant level. Frontiers in Plant Science, $8, \quad 1516$. https://doi.org/10.3389/fpls.2017.01516

Rooney, W. L., Blumenthal, J., Bean, B., \& Mullet, J. E. (2007). Designing sorghum as a dedicated bioenergy feedstock. Biofuels, Bioproducts and Biorefining, 1(2), 147-157. https://doi.org/10.1002/bbb.15

Rutto, L. K., Xu, Y., Brandt, M., Ren, S., \& Kering, M. K. (2013). Juice, ethanol and grain yield potential of five sweet sorghum (Sorghum bicolor [L.] Moench) cultivars. https://doi.org/10.4236/jsbs.2013.32016
Sarsenbayev, B. A., Kirshibayev, E. A., Kamunur, M., Baiseitova, G. A., Sarybaeva, E. A., \& Nokerbekova, N. K. (2013). Biotekhnologiya polucheniya bioetanola iz steblei sorgo sakharnogo (Sorghum saccharatum (L.) Pers.) [Biotechnology of producing bioethanol from the stems of sweet sorghum (Sorghum saccharatum (L.) Pers.)]. Biotechnology, Theory and Practice, 3, 61-64. https://biotechlink.org/3-2013/article10

Shukla, S., Felderhoff, T. J., Saballos, A., \& Vermerris, W. (2017). The relationship between plant height and sugar accumulation in the stems of sweet sorghum (Sorghum bicolor (L.) Moench). Field Crops Research, 203, 181-191. https://doi.org/10.1016/j.fcr.2016.12.004

Tang, S., Wang, Z., Chen, C., Xie, P., \& Xie, Q. (2018). The prospect of sweet sorghum as the source for high biomass crop. Journal Agriculture Science Bottom, 2, 5-11. https://doi.org/10.35841/2591-7897.2.3.5-11

Yucel, C., \& Erkan, M. E. (2020). Evaluation of forage yield and silage quality of sweet sorghum in the eastern Mediterranean region. JAPS, Journal of Animal and Plant Sciences, 30(4), 923-930. https://doi.org/10.36899/japs.2020.4.0108

Zhapayev, R., Iskandarova, K., Toderich, K., Paramonova, I., Al-Dakheel, A., Ismail, S., ... \& Karabayev, M. (2014). Sweet sorghum genotypes testing in the high latitude rainfed steppes of the North Kazakhstan (for feed and biofuel). https://doi.org/10.17265/21625263\%2F2015.01.004 